\title{
REVISÃO: LEITE UHT E O FENÔMENO DE GELATINIZAÇÃO
}

\author{
MÁRCIO FERRAZ CUNHA *
}

\begin{abstract}
Descreve-se neste artigo de revisão, o tratamento térmico "ultra-high-temperature" (UHT), empregado no processamento do leite, bem como seu efeito sobre alguns nutrientes (vitaminas). Também são discutidos os mecanismos envolvidos na gelatinização deste produto, fenômeno que pode reduzir sua vida útil. Em virtude de aumento no consumo do leite UHT e sua importância econômica torna-se indispensável estudar os mecanismos físicos, químicos e bioquímicos relacionados com 0 fenômeno de gelatinização.
\end{abstract}

PALAVRAS-CHAVE: LEITE; UHT; ULTRA-HIGH-TEMPERATURE; GELATINIZAÇÃO.

\section{INTRODUÇÃO}

O emprego do calor é um dos métodos mais antigos utilizados para a conservação de alimentos. Atualmente, no caso específico do leite, um dos processos que tem se destacado na indústria de laticínios é o emprego do processo "ultra-high-temperature" (UHT) ou Ultra-Alta Temperatura (UAT).

No Brasil, após a implementação do Plano Real, houve aumento no consumo de produtos lácteos em geral, principalmente de leite UHT. O expressivo crescimento se deve, principalmente, à redução de preços destes produtos e o conseqüente aumento de poder de compra do consumidor. Além de preço mais acessível, o crescimento do consumo de leite UHT, da ordem de $340 \%$ no período de julho de 1994 a março de 1997, também se deve ao fato de cada vez mais o consumidor procurar produtos que ofereçam maior comodidade (maior vida-de-prateleira) (SEBRAE, 1997; GOMES, 1997). Em trabalho publicado por GOMES (1999) foi demonstrado que o mercado de leite fluido representa $47 \%$ do total de produtos lácteos comercializados no Brasil e que o leite UHT colabora com $25 \%$ desta parcela. Segundo o mesmo autor, no início da

* Professor, Departamento de Biologia e Química, Universidade de ljuí (UNIJUÍ), Campus Santa Rosa (RS); Doutorando, em Ciência e Tecnologia de Alimentos, Universidade Federal de Viçosa, MG. (e-mail: mfcunha@alunos.ufv.br). 
década de $90,4 \%$ das vendas de leite fluido eram provenientes de leite UHT, passando para 53\% no ano de 1998.

Algumas alterações ocorrem com o leite UHT durante a estocagem, como aparecimento do fenômeno de gelatinização e modificações nas propriedades sensoriais, principalmente no sabor. A presença de proteases termorresistentes produzidas por microrganismos psicrotróficos, principalmente do gênero Pseudomonas, e, ou, naturais (plasmina) pode ser um dos fatores responsáveis por estas alterações durante a estocagem do leite UHT (SHAH, 1994; SORHAUG \& STEPANIAK, 1997).

Neste trabalho foram abordados alguns aspectos do processo UHT e o fenômeno de gelatinização associado a este produto.

\section{PROCESSO PARA OBTENÇÃO DO LEITE UHT}

O processo UHT é um tratamento térmico de fluxo contínuo, em que o leite é preaquecido, homogeneizado antes ou após a esterilização, esterilizado, resfriado e embalado assepticamente. Caracteriza-se pelo emprego de temperaturas entre 140 e $150^{\circ} \mathrm{C}$ durante 2 a 4 segundos, para esterilização do produto (SÁ \& BARBOSA, 1990). O Regulamento Técnico de Identidade e Qualidade de Produtos Lácteos (BRASIL, 1996) estabelece como leite UHT "o leite homogeneizado que foi submetido, durante 2 a 4 segundos, a uma temperatura entre 130 e $150^{\circ} \mathrm{C}$, mediante um processo térmico de fluxo contínuo, imediatamente resfriado a uma temperatura inferior a $32{ }^{\circ} \mathrm{C}$ e envasado sob condições assépticas em embalagens estéreis e hermeticamente fechadas".

O processo UHT tem sido objeto de estudo há mais de 100 anos, porém a fabricação e comercialização do leite esterilizado começaram a tomar maior impulso a partir do desenvolvimento de sistemas de fluxo contínuo e asséptico.

Historicamente, somente no início da década de 50, o leite UHT foi produzido em escala industrial. Em 1951, BLOOMBERG \& HESSEY, citados por HOSTETTLER (1981), foram um dos primeiros a descrever 0 processo de produção de leite UHT. Neste processo, o leite era submetido à temperatura de $140,5^{\circ} \mathrm{C}$, durante oito segundos em tubos preaquecidos, sob fluxo contínuo e acondicionado assepticamente em latas.

A indústria sueca Tetra Pak, associada a alguns pesquisadores, 
desenvolveu sistema asséptico para fabricação de leite UHT utilizando embalagens de papelão de forma tetraédrica, esterilizadas por "banho" de água oxigenada. O leite UHT, produzido por este sistema, começou a ser comercializado no ano de 1961, sendo amplamente utilizado até hoje não só na fabricação deste produto (HOSTETTLER, 1981; SÁ \& BARBOSA, 1990).

O processo UHT pode ser realizado pelo sistema direto, em que a esterilização do produto é obtida pela ação do calor proveniente de injeção direta de vapor. Neste sistema, o leite é preaquecido em temperatura entre 70 e $80^{\circ} \mathrm{C}$ e aquecido à temperatura de 130 a $150^{\circ} \mathrm{C}$, durante 2 a 4 segundos pela injeção de vapor quente e homogeneizado. Depois passa pela câmara de vácuo a fim de reduzir a temperatura e eliminar a água do vapor condensado e as substâncias presentes que podem causar odores indesejáveis ao produto. Em seguida, o leite é acondicionado assepticamente em embalagens estéreis e hermeticamente fechadas (LEWIS, 1986; SÁ \& BARBOSA, 1990). Outro sistema empregado para obtenção de leite UHT é o indireto, no qual se utiliza o mesmo princípio de permutação de calor por placas, como na pasteurização, ou melhor, o leite é aquecido pelo calor proveniente de dispositivos metálicos (placas ou tubos) condutores de energia calorífica. Como na pasteurização, o aquecimento destes dispositivos se dá por meio de água quente ou vapor (LEWIS, 1986; SÁ \& BARBOSA, 1990).

O enchimento asséptico consiste em acondicionar o produto já esterilizado em embalagens assépticas. O processo começa com o papelão enrolado que vai aos poucos se transformando em tubo, no qual se coloca o produto. O tubo é fechado lateralmente, por cima ou por baixo, sendo efetuada a esterilização química da embalagem, normalmente com solução de peróxido de hidrogênio. Em seguida, as embalagens são cortadas e modeladas, saindo da máquina prontas para serem encaixotadas, peletizadas e armazenadas (VICENTE et al.,1996).

O tratamento térmico empregado no processo UHT utiliza temperaturas superiores às da pasteurização, embora promova pequenas alterações nas propriedades sensoriais e nutritivas do leite. De acordo com alguns pesquisadores, a pequena redução no valor nutritivo, principalmente de vitaminas, como a vitamina $C$, vitamina $B_{12}$, ácido fólico e vitamina $B_{6}$ é muito influenciada pelas condições de estocagem do produto (BURTON, 1984; LEWIS, 1986; DUNKLEY \& STEVENSON, 1987). O valor nutritivo não é comprometido quando o produto é acondicionado em embalagens hermeticamente fechadas, isentas de oxigênio e opacas (DUNKLEY \& STEVENSON, 1987). 
As vitaminas constituem um dos grupos de nutrientes mais sensíveis aos tratamentos térmicos. A Tabela 1 evidencia que o leite submetido ao processo UHT (direto e indireto) apresenta perdas vitamínicas em pequenas proporções, semelhantes às causadas pela pasteurização (HTST).

\section{TABELA 1 - INFLUÊNCIA DO TRATAMENTO TÉRMICO SOBRE OTEOR VITAMÍNICO DO LEITE E AS PERDAS VITAMÍNICAS (EM PERCENTAGEM) CAUSADAS PELOS PROCESSOS DE PASTEURIZAÇÃO (HTST) E ULTRA-HIGH-TEMPERATURE (UHT)}

\begin{tabular}{l|c|c|c}
\hline \multicolumn{1}{c|}{ VITAMINA } & $\begin{array}{c}\text { LEITE } \\
\text { (por } 100 \mathrm{~mL} \text { ) }\end{array}$ & $\begin{array}{c}\text { HTST } \\
\% \text { de perda }\end{array}$ & $\begin{array}{c}\text { UHT } \\
\% \text { de perda }\end{array}$ \\
\hline Tiamina & 45 microgramas & $<10$ & 10 \\
Riboflavina & 180 microgramas & $\mathrm{ns}$ & $\mathrm{ns}$ \\
cido Nicot nico & 80 microgramas & $\mathrm{ns}$ & $\mathrm{ns}$ \\
Vitamina $\mathrm{B}_{6}$ & 40 microgramas & $<10$ & 10 \\
Biotina & 2,0 miligramas & $\mathrm{ns}$ & $\mathrm{ns}$ \\
cido F lico & 5,0 microgramas & $<10$ & 15 \\
Vitamina C & 2,0 gramas & 20 & 25 \\
Vitamina A & 30 microgramas & $\mathrm{ns}$ & $\mathrm{ns}$ \\
Vitamina D & 22 nanogramas & $\mathrm{ns}$ & $\mathrm{ns}$ \\
Vitamina E & 86 microgramas & $\mathrm{ns}$ & $\mathrm{ns}$ \\
& & &
\end{tabular}

ns $=$ perdas não-significativas.

Fonte: FORD \& THOMPSON, 1981 (modificado).

\section{FENÔMENO DE GELATINIZAÇÃO DO LEITE UHT}

Entre os componentes do leite, as proteínas são as que sofrem maiores 
alterações durante o processo UHT e na estocagem do produto. Modificações nestes componentes podem causar alguns problemas tecnológicos com produtos UHT, como, por exemplo, o aparecimento do fenômeno de gelatinização.

O processo UHT promove alterações na estrutura micelar da caseína (aumento no tamanho da estrutura), aumento no número de pequenas partículas micelares e na quantidade de caseínas solúveis (BURTON, 1984; DUNKLEY \& STEVENSON, 1987; HILL, 1988).

Os tratamentos térmicos mais severos, como o processo UHT, causam desnaturação das proteínas do soro do leite, especialmente a $\beta$ lactoalbumina (MEHTA, 1980). Segundo alguns pesquisadores, o emprego de temperaturas superiores a $70{ }^{\circ} \mathrm{C}$ favorece a interação entre a $\beta$ lactoalbumina desnaturada e a $\kappa$-caseína, formando complexo que compromete a estabilidade da estrutura micelar, por interferir nas interações do fosfato de cálcio com as micelas (MEHTA, 1980; HILL, 1988; SWAISGOOD, 1993). De acordo com HILL (1988) o complexo formado é estabilizado por interações hidrofóbicas, interações iônicas e pontes de dissulfetos. Este autor salienta que a severidade do tratamento térmico aumenta a probabilidade de formação do complexo.

A gelatinização constitui-se num dos principais problemas que afetam a qualidade do leite UHT. O processo UHT promove o aumento da viscosidade do leite, mas não a sua coagulação, já que o tempo de aquecimento é curto. Durante o período de estocagem, a viscosidade do leite aumenta, até a formação do gel (gelatinização), indicando que o produto não está mais apto para o consumo (HILL, 1988).

Os mecanismos envolvidos no fenômeno de gelatinização compreendem basicamente alterações das proteínas do leite, associação e dissociação de íons cálcio, formação de polímeros provenientes da reação de Maillard, formação e dissociação do complexo k-caseína com as proteínas do soro e participação de enzimas naturais do leite (plasmina) e proteases bacterianas (psicrotróficos) (LEWIS, 1986; HILL, 1988).

Alguns pesquisadores acreditam que o fenômeno de gelatinização é induzido, inicialmente, pela ação de enzimas (proteases) termorresistentes presentes, naturalmente, no leite e/ou provenientes de bactérias, principalmente do grupo dos psicrotróficos. Estas enzimas apresentam a capacidade de degradar as caseínas e promover a agregação das micelas do leite. Quando a contagem de bactérias psicrotróficas atinge nível igual 
ou superior a $10^{7}$, a produção de proteases destes microrganismos é capaz de degradar quantidades consideráveis de caseína (SHAH, 1994). Segundo RICHARDSON \& NEWSTEAD (1979) amostras de leite UHT, estocadas à temperatura de $30^{\circ} \mathrm{C}$, que apresentam níveis de protease superiores a 1 nanograma $/ \mathrm{mL}$ podem causar alterações no produto, como aparecimento de sabor amargo e gelatinização.

A ação degradativa das proteases de microrganismos psicrotróficos é distinta entre as frações protéicas do leite. A א-caseína é a fração mais susceptível à ação destas enzimas, seguida em menor escala pelas frações $\alpha$ e $\beta$-caseína, sendo que as proteínas do soro do leite ( $\alpha$-lactoalbumina e $\beta$-lactoglobulina) são resistentes ao ataque das proteases (COX, 1993; SHAH, 1994; SORHAUG \& STEPANIAK, 1997).

Algumas pesquisas relatam que a ação das proteases de bactérias psicrotróficas, principalmente do gênero Pseudomonas, é similar à da quimosina, enzima empregada na coagulação enzimática para obtenção de queijos. Esta atua sobre a א-caseína na ligação peptídica entre o aminoácido fenilalanina na posição 105 e o aminoácido metionina na posição 106, com produção da para-k-caseína e caseinomacropeptídio (CMP) ou glicomacropeptídio (GMP) (MOTTAR et al., 1985; PICARD et al., 1994; PICARD et al., 1996).

Maior rapidez no aparecimento do fenômeno de gelatinização em leite UHT está associada à severidade do tratamento térmico e aos níveis de contaminação de microrganismos psicrotróficos. Amostras de leite, submetidas a tratamento térmico a $75^{\circ} \mathrm{C} / 10$ segundos, gelatinizaram-se após uma semana em temperatura ambiente, quando a contagem de microrganismos psicrotróficos foi da ordem de $10^{9}$. Já no leite aquecido a $135^{\circ} \mathrm{C} / 10$ segundos, este fenômeno ocorreu nas mesmas condições de estocagem, com amostras apresentando contagem de microrganismos psicrotróficos de $10^{8}$ (ADAMS et al., 1976).

Estudos já realizados indicam que a extensão da proteólise é influenciada pelo teor de gordura presente no leite UHT (LOPEZ-FANDIÑO et al., 1993). Em estudo efetuado por GARCIA-RISCO et al.(1999) foi observado que a velocidade da proteólise das amostras de leite UHT desnatadas é superior à de leite integral. Além disso, apresentam maiores proporções de proteínas do soro desnaturadas, quando estocadas a $25^{\circ} \mathrm{C}$ durante cinco meses.

Pesquisas foram realizadas com o objetivo de estudar a ação da plasmina, associada ao tipo de processo UHT (direto ou indireto), temperatura de 
estocagem e presença de ativadores e inibidores da enzima, em relação ao aparecimento da gelatinização (MANJI et al., 1986; KELLY \& FOLEY, 1997). A adição de baixas concentrações de plasmina $(0,15 \mathrm{mg} / \mathrm{L})$ no leite UHT promove a gelatinização do produto após estocagem a $23^{\circ} \mathrm{C}$, durante três meses (KOHLMANN et al., 1991).

Trabalhos sugerem que o fenômeno de gelatinização pode ocorrer devido a mecanismos que envolvem enzimas proteolíticas (naturais do leite, como a plasmina e/ou bacterianas) num primeiro estágio. No segundo estágio, a desestabilização das micelas de caseína é induzida por modificações físico-químicas ocorridas no leite durante sua estocagem (KOCAK \& ZADOW, 1985). KONDAL-REDDY et al. (1991) observaram que o emprego de tratamentos, como o aquecimento a $55^{\circ} \mathrm{C}$, durante 60 minutos e a adição de sais de hexametafosfato de sódio no leite, antes de ser submetido ao processo UHT, promove aumento da vida útil do leite UHT. A adição de polifosfatos previne a agregação das micelas de caseínas, enquanto o tratamento térmico atua inativando as enzimas proteolíticas.

Estudos utilizando a técnica de microscopia eletrônica revelaram que amostras de leite gelatinizadas apresentaram alterações na estrutura micelar da caseína, com a formação de protuberâncias de aspecto flagelar. Tal modificação na estrutura micelar favorece a agregação das micelas, formando o gel. Estas protuberâncias podem ser decorrentes do acúmulo de proteínas dissociadas da micela de caseína, processo que pode ser acelerado pela proteólise da caseína no interior das micelas (VENKATACHALAM et al., 1993).

McMAHON, citado por GARCIA-RISCO et al., (1999), propõe que a gelatinização do leite UHT não se deve ao contato direto entre as micelas de caseína, mas sim à liberação das micelas de caseína de complexos protéicos formados pela $\beta$-lactoglobulina e $\kappa$-caseína que se acumulam no soro até atingirem concentração capaz de formar o gel.

Além da qualidade do leite, principalmente com relação à contaminação de microrganismos psicrotróficos e às respectivas proteases, outros fatores interferem no aparecimento da gelatinização, podendo-se destacar o tipo de processo empregado (direto e indireto) e a temperatura de estocagem.

O leite UHT obtido pelo método direto apresenta maior probabilidade de formar géis, comparado com o método indireto, durante o período de estocagem (SAMEL et al., 1971; BURTON, 1984; MANJl et al., 1986; 
MANJI \& KAKUDA, 1988). Tratamentos térmicos mais severos provavelmente conferem maior resistência às micelas de caseína evitando a sua agregação durante a estocagem.

A estocagem do leite UHT em temperaturas superiores a $35^{\circ} \mathrm{C}$, assim como o emprego de temperaturas de refrigeração, pode retardar o aparecimento do fenômeno de gelatinização (SAMEL et al., 1971; MANJI et al., 1986; MANJI \& KAKUDA, 1988). Estudo realizado por KOCAK e ZADOW (1985) revelou que a estocagem do leite UHT em temperaturas entre 20 e $25^{\circ} \mathrm{C}$ favorece a formação de géis. Reações intramicelares proteína-proteína ocorrem em temperatura igual ou superior a $35^{\circ} \mathrm{C}$, prevenindo o aparecimento do fenômeno (VENKATACHALAM et al., 1993).

\section{CONCLUSÃO}

Embora seja evidente a importância econômica do leite UHT no mercado consumidor de produtos lácteos e na dieta da população brasileira, poucas pesquisas deram ênfase à avaliação da qualidade do produto.

Futuramente devem ser realizados estudos que possibilitem maior compreensão dos fenômenos físicos, químicos e bioquímicos, envolvidos na gelatinização do leite UHT durante sua estocagem, que permitam aferição mais detalhada da qualidade do leite UHT produzido no Brasil.

\section{Abstract}

\section{REVIEW: UHT MILK AND THE AGE GELATION PHENOMENA}

In this review article the ultra-high-temperature treatment in milk processing is described, as well as its effects in some nutrients (vitamins). The mechanisms involved in the age gelation of this product, phenomena that can reduce shelf-life of UHT milk, is discussed. By reason of the increase consumption of UHT milk and your economic importance in Brazil is absolutely necessary future researches of the physical, chemical and biochemical mechanisms related to the age gelation phenomena.

KEY-WORDS: MILK; UHT; ULTRA-HIGH-TEMPERATURE; AGE GELATION.

\section{REFERÊNCIAS}

1 ADAMS, D.M.; BARACH, J.T.; SPECK, M.L. Effect of psichrotrophic bacteria from raw milk on milk proteins and stability of milk proteins 
to ultrahigh temperature treatment. Journal of Dairy Science, Champaign, v.59, n.6, p.823-827, 1976.

2 BRASIL. Ministério da Agricultura. Regulamentos técnicos de identidade e qualidade dos produtos lácteos. Brasília: MAARA/ DAS DIPOA/DNT, 1996. 50 p. (Série Regulamentação Técnica de Identidade e Qualidade de Produtos de Origem Animal).

3 BURTON, $\mathrm{H}$. Reviews of the progress of dairy science: the bacteriological, chemical, biochemical and physical changes that occur in milk at temperatures of $100-150{ }^{\circ} \mathrm{C}$. Journal of Dairy Research, Cambridge, v.51,n.2, p. 341-363, 1984.

4 COX, J.M. The significance of psichrotrophic pseudomonas in dairy products. The Australian Journal of Dairy Technology, Victoria, v. 48, n. 2 , p. 108-112, 1993.

5 DUNKLEY, W.L.; STEVENSON, K.E. Ultra-high temperature processing and aseptic packaging of dairy products. Journal of Dairy Science, Champaign, v.70, n.6, p. 2192-2202, 1987.

6 FORD, J.E.; THOMPSON, S.Y. The nutritive value of UHT milk. Bulletin IDF-FIL, Brussels, n.133, p.65-70, 1981.

7 GARCIA-RISCO, M.R.; RAMOS, M.; LÓPEZ-FANDIÑO, R. Proteolysis, protein distribution and stability of UHT milk during storage at room temperature. Journal of the Science of Food and Agriculture, Philadelphia, v. 79, n. 9, p.1171-1178, 1999.

8 GOMES, S.T. Cadeia agroindustrial do leite no Mercosul. In: VIEIRA, Wilson; CARVALHO, Fátima de. Mercosul: agronegócios e desenvolvimento econômico. Viçosa, MG: Departamento de Economia Rural - UFV, 1997. p. 155- 175.

9 GOMES, S. T. Efeitos da globalização na produção de leite do Brasil. Informe Agropecuário, Belo Horizonte, v. 20, n.199, p.93102, 1999.

10 HILL, A. Quality of ultra-high-temperature processed milk. Food Technology, Chicago, v.12, n.9, p. 92-97, 1988.

11 HOSTETTLER, $\mathrm{H}$. History of the development of UHT processes. 
Bulletin IDF-FIL, Brussels, n.133, p.132-134, 1981.

12 KELLY, A.L.; FOLEY, J. Proteolysis and storage stability of UHT milk as influenced by milk plasmin activity, plasmin/ lactoglobulin complexation, plasminogen activation and somatic cell count. International Dairy Journal, Oxford, v.7, n.6-7, p.411-420, 1997.

13 KOCAK, H. R.; ZADOW, J.G. Age gelation of UHT whole milk as influenced by storage temperature. The Australian Journal of Dairy Technology, Victoria, v.40, n.1, p. 14-21, 1985.

14 KOHLMANN, K.L.; NIELSEN, S.S.; LADISCH, M.R. Effects of a low concentration of added plasmin on ultra high temperature processed milk. Journal of Dairy Science, Champaign, v. 74, n.4, p. 11511156, 1991.

15 KONDAL-REDDY, K. et al. The effects of some treatments and storage temperatures on UHT whole milk. The Australian Journal of Dairy Technology, Victoria, v.46, n.2, p. 57- 63, 1991.

16 LEWIS. M.J. Advances in heat treatment of milk. In: MODERN dairy technology. Essex, England: Elsevier Applied Science, 1986. p. 150. ( v.1-Advances in Milk Processing).

17 LÓPEZ-FANDIÑO, R.; OLANO, A.; CORZO, N.; RAMOS, M. Proteolysis during storage of UHT milk: differences between whole and skim milk. Journal of Dairy Research, Cambridge, v. 60, n. 3, p. 339-347, 1993.

18 MANJI, B.; KAKUDA, Y.; ARNOTT, D.R. Effect of storage temperature on age gelation of ultra-high temperature milk processed by direct and indirect heating systems. Journal of Dairy Science, Champaign, v. 69, n.12, p. 2994-3001, 1986.

19 MANJI, B.; KAKUDA, Y. The role of protein denaturation, extent of proteolysis, and storage temperature on the mechanism of age gelation in model system. Journal of Dairy Science, Champaign,v. 71, n.6, p. 1455-1463, 1988.

20 MEHTA, R.S. Milk processed at ultra-high-temperature: a review. Journal of Food Protection, Des Moines, v.43, n.3, p.212-225, 1980. 
21 MOTTAR, J.; VAN RENTERGHEM, R.; VILDER, J. de. Evaluation of the raw material for UHT milk by determining the degree of protein breakdown through HPLC. Milchwissenschaft, Muenchen, v.40, n.12, p. 717-721, 1985.

22 PICARD, C.; PLARD, I.; RONGDAUX-GAIDA, D.; COLLIN, J.C. Detection of proteolysis milk stored at low temperature by an inhibition ELISA. Journal of Dairy Research, Cambridge, v.61, n.3, p. 395404, 1994.

23 PICARD, C.; PLARD, I.; COLLIN, J.C. Application of the inhibition ELISA method to the study of proteolysis caused by heat-resistant Pseudomonas proteinases specific towards k-casein in heated milk. Milchwisssenschaft, Muenchen, v. 51, n.8, p. 438-442, 1996.

24 RICHARDSON, B. C.; NEWSTEAD, D. F. Effect of heat-stable proteases on storage life of UHT milk. New Zealand Journal of Dairy Science and Technology, Palmerston North, v. 14, n. 3, p.273-279, 1979.

25 SÁ, F.V. de; BARBOSA, M. O leite e os seus produtos. 5. ed. Lisboa, Portugal: Clássica, 1990. 519 p.

26 SAMEL, R.; WEAVER, R.W.V.; GAMMACK, D. B. Changes on storage in milk processed by ultra-high-temperature sterilization. Journal of Dairy Research, Cambridge, v. 38, n. 3, p. 323-332, 1971.

27 SEBRAE. Serviço de Apoio às Micro e Pequenas Empresas de Minas Gerais. Diagnóstico da indústria de laticínios do Estado de Minas Gerais. Belo Horizonte: SEBRAE-MG, 1997. 270 p.

28 SHAH, N.P. Psychrotrophs in milk: a review. Milchwissenschaft, Muenchen, v.49, n.8, p.432-437, 1994.

29 SORHAUG, T.; STEPANIAK, L. Psychrotrophs and their enzymes in milk and dairy products: quality aspects. Trends in Food Science \& Technology, Oxford, v.8, p. 35-41, 1997.

30 SWAISGOOD, H.E. Caracteristicas de los fluidos nutritivos de origen animal: leche. In: FENNEMA, O.R. Química de los alimentos. 2. ed. Zaragoza: Acribia, 1993. p. 889-930. 
31 VENKATACHALAM, N.; McMAHON, D. J.; SAVELLO, P.A. Role of protein and lactose interaction in the age gelation of ultra-hightemperature processed concentrated skim milk. Journal of Dairy Science, Champaign, v. 76, n.7, p. 1882-1894, 1993.

32 VICENTE, A.; CENZANO, I. ; VICENTE, J. M. Manual de indústrias dos alimentos. São Paulo: Varela, 1996. 599 p. 